\title{
Programa Integração: avanços e contradições de uma proposta de educação formulada pelos trabalhadores*
}

Sonia Maria Rummert

Universidade Federal Fluminense, Faculdade de Educação

\section{Introdução}

A educação de básica de jovens e adultos trabalhadores tem constituído, desde meados da década de 1990, objeto de interesse e diferentes iniciativas por parte de entidades representativas da classe trabalhadora no Brasil. De forma sintética, podemos afirmar que esse fato decorreu, predominantemente, de dois fatores complementares. O primeiro refere-se à forte presença da temática educacional nos discursos hegemônicos que vinculam, de forma direta, a educação e a elevação de escolaridade à superação das profundas desigualdades sociais, que constituem marca da estrutura socioeconômica do país. O segundo, decorrente do primeiro, localiza-se na política de formação profissional implementada pelo governo fe-

* Este artigo apresenta parte dos resultados da pesquisa Educação básica, formação técnico-profissional e identidade de trabalhadores; o caso das Telecomunicações no Rio de Janeiro, realizada no período de março de 2002 a fevereiro de 2004, com o apoio do CNPq. deral a partir de 1995, por meio do PLANFOR, ${ }^{1}$ que possibilitou às entidades sindicais acesso a significativo volume de recursos financeiros oriundos do Fundo de Amparo ao Trabalhador (FAT), para desenvolver ações no âmbito da educação dos trabalhadores.

A participação das entidades sindicais no PLANFOR, especialmente daquelas que se apresentam formalmente como combativas em relação ao capital, tem sido compreendida por muitos como uma prática questionável e perigosa, que desvirtua o caráter daquelas entidades, chegando mesmo a adquirir marcas de cooptação. Em contrapartida, há uma forte corrente que considera necessário e pertinente que elas, explorando o caráter contraditório do real, de-

1 A sigla PLANFOR refere-se, indistintamente, nos documentos oficiais, tanto a Programa de Nacional de Formação Profissional quanto a Plano Nacional de Formação Profissional. O PLANFOR foi instituído pela resolução $n^{\circ}$ 126/96 do Conselho Deliberativo do Fundo de Amparo ao Trabalhador (CODEFAT), está subordinado ao Ministério do Trabalho e Emprego (MTE) e opera com recursos do Fundo de Amparo ao Trabalhador (FAT). 
senvolvam ações educativas voltadas para os interesses dos trabalhadores.

Avaliar os riscos e as potencialidades da participação das entidades sindicais no PLANFOR, entretanto, não constitui objetivo deste estudo, embora seja indiscutível a importância e a necessidade dessa análise para a compreensão das características e caminhos que vem assumindo o movimento sindical brasileiro, na atual fase de expansão e consolidação do capital, na qual se vivencia a hegemonia da lógica do mercado e da economia competitiva, o expressivo aumento do desemprego estrutural e a precarização das relações de trabalho.

Com base na reflexão acerca de alguns aspectos referentes a uma dessas experiências, pretendemos, neste artigo, apresentar os nexos entre concepções político-ideológicas e a formulação de propostas para a educação de jovens e adultos trabalhadores, destacando contribuições e impasses que tais iniciativas apresentam para essa modalidade de ensino, que deve ser compreendida, historicamente, no quadro socioeconômico do país, como uma educação de classe. ${ }^{2}$

O artigo analisa, assim, o Programa Integração, uma iniciativa educacional tomada pela Central Única dos Trabalhadores (CUT), sob responsabilidade direta de sua Secretaria Nacional de Formação (SNF). Este Programa, implementado no período de 2000 a

2 Consideramos importante não incorrer no equívoco, hoje recorrente, que focaliza a problemática da educação de jovens e adultos apenas a partir das questões relativas, por exemplo, à raça, à etnia ou ao gênero, as quais, apesar de sua fundamental importância, não contemplam a essência da problemática dos alunos dessa modalidade de ensino, que reside, precisamente, no fato de serem, em expressiva maioria, oriundos da classe trabalhadora, para a qual a oferta de possibilidades de acesso e de permanência na escola é historicamente regulada pelos interesses do capital. Se hoje o ordenamento societário confere menos visibilidade à estrutura de classes de nossa sociedade, isso não pode ser tomado como superação dessa mesma estrutura. Ignorar tal fato concorre, de modo substantivo, para a afirmação dos interesses dominantes, que mais consolidam sua hegemonia quanto mais se afirma a fragmentação societária.
2002, foi desenvolvido em 11 estados brasileiros, por confederações e federações de 13 diferentes ramos produtivos, filiadas à CUT, visando propiciar aos trabalhadores formação profissional e elevação de escolaridade no nível do ensino fundamental ou médio. ${ }^{3}$

Entre as entidades envolvidas, destacamos a $\mathrm{Fe}$ deração Interestadual dos Trabalhadores em Telecomunicações (FITTEL), que teve papel relevante na decisão de que o Programa contemplasse também o ensino médio, dado o grau de escolaridade da maioria dos trabalhadores do ramo da Telemática. Foi a FITTEL, ainda, que indicou como um dos executores do Programa o Sindicato dos Trabalhadores em Telecomunicações do Rio de Janeiro (SINTTEL-RJ), para implementar o Programa Integração (de Elevação de Escolaridade e Qualificação Profissional Básica em Telemática). A escolha do SINTTEL-RJ decorreu, entre outros aspectos, do fato de que a entidade se envolve com a problemática educacional desde o ano de 1993, quando assumiu a direção do Colégio Graham Bell, que hoje oferece ensino médio e técnico em telecomunicações e informática.

No presente estudo abordaremos, especificamente, o Programa Integração - Ramo Telemática, implementado pelo SINTTEL-RJ. Para tanto, apresentaremos inicialmente breves considerações acerca do setor de telecomunicações no Brasil atual, e, a seguir, algumas referências à CUT, a fim de propiciar melhor compreensão do quadro em que se inscreve a iniciativa de oferta de elevação de escolaridade para os trabalhadores e de questões que essa prática suscitou.

\section{Breve abordagem das telecomunicações no Brasil atual}

A compreensão da problemática brasileira das telecomunicações deve situar-se no quadro de mu-

3 Foram formadas, em 11 estados do país, 120 turmas de ensino fundamental e 57 turmas de ensino médio, cada uma com aproximadamente 30 alunos. A carga horária foi estabelecida em 816 horas para o ensino fundamental e em 1.030 para o ensino médio (Barbara, Miyashiro \& Garcia, 2004, p. 32). 
danças por que passa o setor em nível internacional, e que são condicionadas pelas transformações ocorridas no capitalismo mundial desde os anos de 1970. A tais mudanças, de caráter político-econômico, somam-se também, com importante significação, as de cunho científico-tecnológico, que provocaram a passagem do sistema operacional analógico para o digital e a introdução da fibra ótica.

Esse complexo quadro imprimiu às telecomunicações importância fundamental para a própria sustentabilidade da nova face globalizada do capitalismo contemporâneo, ao mesmo tempo em que tornou o setor em negócio significativamente valorizado no mercado internacional. Tal processo alçou as telecomunicações, da posição de insumo aos demais setores, para a situação de setor de ponta da economia. ${ }^{4}$ Podemos, assim, afirmar que as tecnologias de que se valem hoje as telecomunicações "produzem novos tipos de bens e são úteis para abrir novos espaços no mundo, 'encolhendo' dessa forma o globo e reorganizando o capitalismo de acordo com uma nova escala" (Jameson, 1999, p. 188).

É nesse quadro que o setor foi regulado, tendo sua organização e seu funcionamento ordenados de modo que garanta o atendimento aos interesses do capital, segundo as relações estabelecidas no quadro hegemônico internacional. Em decorrência, as telecomunicações foram significativamente atingidas pela racionalização e reestruturação do trabalho, tanto pelo baixo assalariamento como pelo trabalho terceirizado e precarizado. O setor também é hoje fortemente marcado pela hipertrofia do trabalho-morto. Todas essas manifestações se apresentam como dimensões orgânicas da lógica da racionalização dominante e resultaram em fortes impactos para a categoria dos trabalhadores em telecomunicações, em particular a partir dos anos de 1990.

A desestruturação que atingiu o movimento sindical dessa categoria e a própria instabilidade que passou a marcar a vida dos trabalhadores do ramo

\footnotetext{
4 Ver Almeida (1994), Dantas (1996) e Rodrigues (2002).
}

exemplificam, com clareza, o que Boaventura Santos denominou como o "fascismo da insegurança":

\begin{abstract}
[...] grupos sociais vulnerabilizados pela precariedade do trabalho que manifestam elevados níveis de ansiedade e insegurança quanto ao presente e ao futuro, de modo a fazer baixar o horizonte de expectativas e a criar a disponibilidade para suportar grandes encargos, de modo a obter reduções mínimas dos riscos e da insegurança. (apud Frigotto, 1999, p. 54)
\end{abstract}

Os aspectos mencionados são fundamentais para a compreensão da atuação da FITTEL e do SINTTELRJ no âmbito da educação dos trabalhadores da categoria. Essa compreensão também exige que se estabeleçam as necessárias relações com o quadro de transformações ocorridas, ao longo década de 1990, no movimento sindical, em particular no âmbito da CUT, à qual estão filiadas as entidades a que nos referimos.

Para os fins deste artigo, basta mencionar o tensionamento interno entre a postura propositiva, que defende as teses do sindicalismo cidadão e participativo nas iniciativas implementadas pelo Estado, e a postura reativa, centrada nos pressupostos do sindicalismo classista. ${ }^{5}$ Tais tensionamentos, associados ao processo de desarticulação vivenciado pelas entidades sindicais combativas, em decorrência da hegemonia do modelo neoliberal e de tudo que dela adveio - inclusive a incorporação de fundamentos de sua "cultura-ideologia" (Jameson, 1994) -, repercutiram, evidentemente, na formulação das propostas para a política de telecomunicações no país, nas formas de enfrentamento e/ou convivência com as mudanças efetivadas pelo Estado e, com a mesma intensidade, nas propostas formuladas e nas ações executadas pela CUT, pela FITTEL e pelo SINTTELRJ, no âmbito da educação de jovens e adultos trabalhadores.

\footnotetext{
5 Sobre a postura propositiva da CUT, ver Affonso (2001).
}

A crítica a essa postura e os fundamentos da perspectiva classista estão claramente explicitados em Tumolo (2002). 
A privatização do setor das telecomunicações, em 1998, e sua quase total desnacionalização trouxeram contornos específicos para a composição da correlação de forças no âmbito da categoria. Um deles explicita-se no fato de que o embate entre a postura propositiva e a classista tornou-se menos acirrado do que em outros campos da CUT. ${ }^{6}$ Além disso, destacase a grande transformação ocorrida no perfil da categoria, que sofreu significativa alteração quantitativa e qualitativa, como apontado anteriormente, em decorrência da grande redução dos postos de trabalho e do intenso e desordenado processo de precarização e terceirização, que rompeu os laços entre os trabalhadores e as entidades sindicais deles representativas.

A forma como o movimento sindical do ramo apreende o processo brevemente mencionado acima, e como se move em relação à educação nessa complexa realidade, é explicitada na justificativa formulada pelo Instituto de Telecomunicações do Rio de Janeiro (INTEL) (criado pelo SINTTEL-RJ), na Proposta de Qualificação Profissional na Área de Telecomunicações, apresentado ao Ministério do Trabalho e Emprego (MTE) em 1999 para obtenção de recursos do FAT. Depois de destacar o papel assumido pelas telecomunicações nas mudanças econômicas ocorridas no Brasil nos anos de 1990, é afirmado que "junto com a informática, esta área foi fundamental para a reestruturação produtiva nas empresas e para o processo de globalização da economia". A seguir, afirma-se que a rapidez das transformações, entre as quais é realçado o processo de privatização, trouxe como uma das principais consequiências "o temor do desemprego por parte dos trabalhadores. Pela extinção de sua função, ou mesmo pela sua desatualização frente às inovações tecnológicas". Continuando a justificativa, é apresentada adiante a argumentação norteadora de boa parte das ações voltadas para a educação de trabalhadores no ramo produtivo em destaque e também em muitos outros:

\footnotetext{
6 Ver Rodrigues (2002).
}

Mas ao mesmo tempo que o fantasma do desemprego vem rondando nossos trabalhadores, pelos motivos citados acima, este é um setor em expansão e poderá empregar, ainda que não da forma tradicionalmente estabelecida, um número significativo de trabalhadores. [...] Apesar de termos uma posição crítica à idéia que se criou em torno da Qualificação Profissional como salvação para todos os males do trabalhador, não queremos nos eximir de apresentar propostas para um período extremamente difícil para os trabalhadores e, conseqüentemente, para os Sindicatos. (INTEL/ SINTTEL-RJ, 1999, p. 5)

Percebe-se, nos trechos citados, a dubiedade da argumentação que, ao mesmo tempo: destaca a positividade da globalização e da reestruturação produtiva e a importância do ramo para sua implementação, embora sejam conhecidos os efeitos perversos dos processos assinalados para a classe trabalhadora; aceita como inexorável a existência do trabalho terceirizado e precarizado ao acenar com as possibilidades da obtenção de renda "ainda que não da forma tradicionalmente estabelecida"; e, finalmente, apresenta as iniciativas de qualificação profissional como uma forma da entidade estar ao lado dos trabalhadores em fase tão adversa.

Não é objetivo do presente artigo analisar a complexidade do momento histórico vivido pela classe trabalhadora e por suas entidades representativas. Tampouco é possível, aqui, aprofundar os diferentes significados e as distintas intencionalidades das propostas apresentadas pela CUT e pelos sindicatos a ela filiados acerca da educação dos trabalhadores. Consideramos, entretanto, que o documento destacado anteriormente exemplifica, com propriedade, as dificuldades e os conflitos vivenciados pelos trabalhadores e por suas lideranças, quando, por opção ou por falta de perspectivas de curto e médio prazos, exercitam a tentativa de adaptação política e institucional a um modelo socioeconômico centrado na manutenção das bases estruturais do capitalismo, em sua atual fase de expansão.

Deve-se destacar ainda o fato de que, em seus documentos propositivos, a FITTEL, o SINTTEL-RJ 
e o INTEL apresentam densa reflexão sobre as questões de caráter científico-tecnológico no âmbito das telecomunicações, sistematizada em diversos documentos por elas produzidos. ${ }^{7}$ Nesse conjunto de documentos destaca-se a ênfase dada à importância da capacitação tecnológica do Brasil no campo das telecomunicações, o que implica, entre outros pontos: ampliação da produção interna, apoio à produção tecnológica nacional e política específica de geração de emprego.

Tais aspectos exigem, necessariamente, a canalização de esforços no sentido de dotar o país de maior quadro de trabalhadores qualificados para atender demandas a serem criadas, caso as propostas apresentadas pelas entidades sindicais viessem a ser acolhidas pelas políticas governamentais. Pode-se, assim, considerar que as iniciativas de educação dos trabalhadores no ramo das telecomunicações desenvolvidas por essas entidades sindicais devam concorrer, de modo significativo, para tal qualificação dos trabalhadores. Veremos, posteriormente, no caso específico do Programa Integração - Ramo Telemática, como tal processo se verificou.

\section{O Programa Integração da CUT como expressão de contradições}

A postura propositiva incorporada pela CUT no campo da qualificação profissional e da elevação de escolaridade dos trabalhadores só adquiriu efetiva materialidade em decorrência dos recursos disponibilizados pelo FAT para a implementação do PLANFOR. Não resultou, portanto, de um expressivo processo de compreensão, por parte das entidades cutistas, em particular, sobre a importância da problemática da educação básica, ${ }^{8}$ em decorrência de seu papel essencial para

7 Também a CUT elaborou estudo sobre o setor, desenvolvido em convênio com a FINEP, contemplando ainda outros ramos produtivos (2000).

8 No que se refere aos estudos e às propostas relativas à formação profissional, ver Manfredi (2002, p. 249-267), que destaca a formação integral dos trabalhadores. Embora seja inegável o acúmulo que a CUT obteve, ao longo da década de 1980, em suas ações destinadas à formação sindical, o que conferiu às propostas de escolarização uma densidade teórico-metodológica inovadora, é necessário registrar o fato de que, anteriormente ao PLANFOR, os debates acerca da temática educacional, sobretudo os referentes à educação básica, ficavam, no mais das vezes, circunscritos às entidades representativas dos profissionais da educação.

Apesar de decorrer de um desencadeador externo - o PLANFOR - que possibilitou à CUT o acesso a um montante significativo de recursos, ${ }^{9}$ a proposição de ações na área da formação profissional promoveu maior envolvimento global da entidade nacional, e daquelas a ela filiadas, com os temas e problemas da educação, em particular com a educação de jovens e adultos, uma vez que, ao lado da formação profissional, se fazia presente a necessidade de elevação da escolaridade dos trabalhadores. ${ }^{10}$

Nesse quadro, dois outros aspectos ainda merecem destaque. $\mathrm{O}$ primeiro refere-se ao fato de que, em muitos casos, a oferta de cursos representa um caminho para os sindicatos criarem novos laços com suas bases, uma vez que os anteriores foram comprometidos ou mesmo rompidos em decorrência da hegemonia do ideário neoliberal e do que dela adveio (como anteriormente mencionado), ou do próprio ana-

o fato de que datam de 1992 a formação de grupos de trabalho e os documentos iniciais acerca da temática.

9 É importante ressaltar que, ao longo da vigência do PLANFOR, embora os valores tenham se alterado de modo significativo a cada ano, comparativamente, a CUT recebeu uma parcela pequena de recursos, em relação, por exemplo, ao recebido pelo Sistema S, e menos do que a Força Sindical. Tais recursos, entretanto, eram bastante expressivos para a entidade num período de ampla retração do emprego formal e, conseqüentemente, de redução de arrecadação pelas entidades sindicais.

${ }^{10}$ A respeito do impacto que o PLANFOR representou para a CUT e demais centrais sindicais, ver, por exemplo, Manfredi (2002). 
cronismo de algumas de propostas e práticas. O segundo aspecto diz respeito ao volume de recursos destinados à CUT para o desenvolvimento das ações educativas, que, ao longo dos anos, supera, em muito, o orçamento anual das entidades sindicais, sobretudo num quadro de acentuado desemprego e conseqüente redução drástica de arrecadação. Tal aspecto mobilizou de forma significativa vários setores da CUT, que viram no FAT uma via de ampliação de recursos para o movimento sindical.

A esses aspectos faz-se necessário acrescentar a importância de compreendermos que as ações sempre explicitam a leitura que se faz da realidade, marcada, evidentemente, por uma opção política. A opção política de que tratamos aqui, propositiva no campo da educação dos trabalhadores, expressa também a prevalência do ideário partilhado pela corrente hegemônica no âmbito da CUT - a articulação sindical.

É no âmbito dessa corrente que se encontram as mais veementes defesas da importância das ações educativas destinadas aos trabalhadores desenvolvidas no interior do movimento sindical, tendo como parâmetro de argumentação um discurso que incorpora elementos do ideário liberal e neoliberal, relacionando, mesmo que de forma indireta, elevação de escolaridade e formação profissional com obtenção de emprego e melhoria das condições de vida (aqui compreendida como elevação de salário ou de ganhos de diferentes ordens), evidenciando-se a incorporação de crenças largamente difundidas, nas últimas décadas, fundadas na Teoria do Capital Humano, agora revisitada.

Não é demais citar, a título de exemplo, pequenos trechos de uma cartilha distribuída pelo Programa Integração da CUT, destinada aos trabalhadores, na qual se afirma, por exemplo: "Tem que investir na educação dos trabalhadores para eles acompanharem as mudanças que estão acontecendo nas fábricas e nas empresas. O governo precisa apoiar novas alternativas de desenvolvimento, oferecendo aos trabalhadores outras fontes de renda" (CUT/Integração, 2000, p. 2). Mais adiante, na mesma cartilha, diz-se: “com os programas de formação da CUT, os trabalhadores podem até conquistar o certificado de primeiro grau ou de segundo grau. Podem até entrar para a faculdade. Para a CUT, esse é um dos caminhos que pode ajudar o trabalhador brasileiro a se tornar um cidadão pleno e ter qualidade de vida melhor" (idem, p. 4).

Em contrapartida, a mesma cartilha alerta também para o fato de que a qualificação profissional pode ajudar muito ao trabalhador, "mas não garante o emprego de ninguém" (idem, p. 2). Entretanto, ao apontar novos caminhos, enfatiza possibilidades alternativas, apontando para a "produção em cooperativas e associações, e até empresas gerenciadas pelos próprios trabalhadores [...]. É a tal da 'economia solidária"” (idem, p. 3).

Em que pese a pertinência de diversas críticas a essas propostas, não podemos ignorar que se por um lado o PLANFOR é, "por excelência, uma espécie de baú de venda de ilusões face ao fascismo da insegurança" (Frigotto, 1999, p. 55), por outro, não podemos ignorar também que, na multiplicidade de iniciativas por ele geradas, encontramos formas de explicitação da categoria essencial do materialismo histórico: a contradição. Assim, foram forjadas, por iniciativa dos trabalhadores, como também reconhece o autor citado, significativas experiências de educação de trabalhadores como as do "projeto Integrar, sob a orientação dos Sindicatos dos Metalúrgicos, e outras iniciativas similares dos Sindicatos dos Bancários e das Telecomunicações" (idem, ibidem). É precisamente a partir da análise do Programa Integração Ramo Telemática, realizado pelo SINTTEL-RJ, que se pode evidenciar as potencialidades dessas contradições.

\section{Os educandos do Integração - Ramo Telemática do SINTTEL-RJ ${ }^{11}$}

Os dados aqui apresentados, referentes ao Programa Integração - Ramo Telemática, do SINTTEL-

11 Informações sobre os egressos dos cursos oferecidos pela CUT com financiamento do FAT podem ser obtidas em CUT (2003). 
RJ, foram obtidos a partir das informações fornecidas por 267 alunos, à época da matrícula, no preenchimento de cadastro elaborado pela CUT/PLANFOR/ MTE. Do total de cadastros analisados, apenas $44,2 \%$ (118) ofereciam informações acerca da ocupação/profissão. Desse conjunto, apenas 20,3\% (55) eram oriundos da categoria dos trabalhadores em telecomunicações. Os demais eram vinculados a outros ramos ou sem qualquer qualificação específica. A pesquisa permitiu ainda, a partir de informações da Secretaria Nacional de Formação (SNF), identificar que esse perfil dos alunos não era típico apenas do Ramo Telemática, mas de todos os treze ramos produtivos para os quais o Programa foi planejado. Ou seja, os trabalhadores dos ramos produtivos cujas entidades de classe ofereceram o curso de elevação de escolaridade com qualificação profissional, representaram, em média, apenas $20 \%$ dos educandos atendidos.

Outra informação a destacar diz respeito ao fato de que dos 196 alunos que declararam sua situação no mercado de trabalho no momento da matrícula, apenas $63(32,1 \%)$ eram empregados assalariados, com carteira assinada.

No que diz respeito à média de renda (própria e/ ou familiar), 71 alunos informaram que sua renda correspondia a uma faixa de $\mathrm{R} \$ 100,00$ a $\mathrm{R} \$ 300,00$ mensais. A renda de 77 alunos variava entre $R \$ 301,00$ e $\mathrm{R} \$ 500,00$ mensais, e a de 60 correspondia à faixa de $\mathrm{R} \$ 501,00$ a $\mathrm{R} \$ 800,00$. Assim, do universo de respostas a esse item, 51\% dos alunos (198) indicaram possuir renda igual ou menor que $\mathrm{R} \$ 500,00$.

Com relação à existência de vínculo com entidades sindicais, apenas 186 cadastros registravam respostas. Dessas, 142, ou seja, 76,3\%, indicavam não haver qualquer tipo de vínculo sindical, enquanto $23,6 \%$ (44 respostas) informavam que os alunos desenvolviam algum tipo de militância sindical. Faz-se necessário, entretanto, explicitar o fato de que como militância era compreendido, no momento de preenchimento do cadastro, segundo informações da secretaria do Programa, desde o aluno que era um militante ativo até aquele que havia procurado o curso por indicação de conhecidos ou parentes envolvidos com o movimento sindical. De tais dados é possível depreender que nem mesmo os $23,6 \%$ que responderam positivamente ao item eram, efetivamente, envolvidos com o movimento sindical. ${ }^{12}$

Ao longo do acompanhamento do curso, foram aplicados outros instrumentos de pesquisa que forneceram informações acerca dos alunos. Uma delas diz respeito às motivações que os levaram a procurar o Programa. De um universo de 113 questionários aplicados ao final do ano de 2002, apenas cinco alunos indicaram ter procurado o Integração por ser o mesmo oferecido pela CUT. Verificamos, assim, que para os alunos do Programa Integração - Ramo Telemática do SINTTEL-RJ, o fato de o Programa ser oferecido por uma entidade sindical pouco significou na motivação por sua procura. Os fatores determinantes da escolha foram: a oportunidade de concluir em menor tempo o ensino médio (ao qual se referiram como segundo grau, do mesmo modo que a cartilha distribuída pelo Integração), com 43 respostas; a gratuidade por vezes acrescida de referências ao vale-transporte e ao lanche - foi apontada por 37 alunos. As outras 28 respostas referiram-se, genericamente, ao desejo de ampliar os conhecimentos e ao fato de o curso se apresentar como uma ótima oportunidade para tanto.

Esse aspecto evidencia o fato de que, ao aceitar alunos indistintamente, por entender que havia um trabalho importante a ser realizado - elevar a escolaridade de trabalhadores a partir de uma proposta diversa das ofertadas pelas redes de ensino, independentemente de sua origem ou vinculação profissional - e também de modo a não perder os recursos do FAT destinados à realização do projeto, a CUT deixou de operar a partir de seus eixos estruturantes: os ramos profissionais organizados em sindicatos, federações e confederações, para atuar como rede de ensino, aberta indistintamente à população com baixa escolaridade.

Dos dados expostos anteriormente, outro aspecto se destaca: o fato de que o curso ser promovido por

12 Para maior detalhamento dos dados indicados, ver Silva (2004). 
uma entidade sindical filiada à CUT não representou fator de mobilização ou atrativo suficiente para os trabalhadores. Tal constatação aponta para a necessidade de questionar o atual alcance da CUT e, em particular, no caso aqui analisado, do SINTTEL-RJ, no sentido de atingir e mobilizar efetivamente as frações da classe trabalhadora às quais o Programa se destinava especificamente. No caso das telecomunicações, chama a atenção a pouca participação de trabalhadores da categoria no universo de alunos matriculados, embora o ramo ainda conte com significativo contingente de trabalhadores, no Rio de Janeiro, que não possuem certificação de ensino médio (o que se tornará indispensável, em curto prazo, no estado, mesmo para o trabalho em empresas terceirizadas e empreiteiras).

Essa ausência de trabalhadores da área, pelo que foi identificado na pesquisa, pode ser explicada por dois motivos básicos: o primeiro diz respeito ao fato de que os canais de comunicação entre a entidade e sua base, na atual conjuntura, não são suficientes ou satisfatórios e não estão estruturados de modo a fazer frente à descaracterização e pulverização da categoria, advindas do processo de privatização do setor, fato reconhecido pelos próprios dirigentes sindicais em depoimentos a nós concedidos. O segundo decorre das próprias condições de trabalho da categoria, que muitas vezes não dispõe de condições para freqüentar o ensino noturno, tanto pela sobrecarga de trabalho quanto por residir em locais distantes daquele em que o curso foi oferecido.

\section{Avanços e limites no campo teórico-metodológico ${ }^{13}$}

O Programa Integração oferece significativas contribuições teórico-metodológicas à educação de jovens e adultos trabalhadores. Tais contribuições,

${ }^{13} \mathrm{Na}$ impossibilidade de descrevermos a proposta pedagógica do Programa Integração, remetemos os leitores aos trabalhos de Barbara, Miyashiro e Garcia (2004) e Manfredi (2002). embora ainda careçam, por parte de seus formuladores e executores, de maior aprofundamento teórico, bem como de mais acurada análise crítica tanto do processo como dos resultados obtidos, trazem, na abordagem inovadora, importantes elementos, cujos fundamentos podem ser incorporados a um estatuto teórico-metodológico próprio para essa modalidade de ensino. Nessa perspectiva, sua implementação trouxe à tona a fecundidade de reflexões e experiências do movimento cutista no campo da formação sindical, que inspiraram, em parte, as propostas pedagógicas apresentadas.

Deve-se destacar, inicialmente, a matriz curricular do Integração, que, rompendo com a lógica do ordenamento disciplinar, objetivou propiciar aos educandos um percurso formativo centrado nas "relações e inter-relações com a vida concreta dos trabalhadores jovens e adultos, partindo e dialogando com conhecimentos trazidos por esses sujeitos para a reflexão sobre a realidade na qual estão inseridos" (Barbara, Miyashiro \& Garcia, 2004, p. 35). Segundo seus formuladores, em decorrência da perspectiva teórico-metodológica em que se fundamentou, a abrangência nacional do Programa constitui fator de enriquecimento pedagógico, visto que as ricas e diversificadas experiências socioculturais de educandos e educadores foram consideradas como parte integrante do conjunto de elementos formativos no permanente processo de construção curricular.

Dois pontos de referência se destacam na elaboração do currículo. O primeiro refere-se ao fato de que a proposta tomou, como eixo fundamental, o trabalho, compreendido como processo histórico de transformação da natureza e dos próprios homens, os quais, em sociedade, criam, por múltiplas formas de sociabilidade, os diferentes modos de produção e compreensão da existência. A partir dessa perspectiva, foram focalizadas, em sua complexidade, as características assumidas pelo trabalho nas sociedades capitalistas, ressaltando-se que estas, frutos de processo histórico, são passíveis de transformações decorrentes do agir humano.

O segundo ponto parte da compreensão de que o 
"conhecimento não pode ser concebido como algo externo e distante dos sujeitos, apartado das relações sociais que o constituem" (idem, p. 39). Assim sendo, sua apropriação e produção não decorrem da incorporação mecânica de conteúdos, apartados dos processos sócio-históricos em que são produzidos. Visando propiciar as condições pedagógicas necessárias à efetiva apropriação e produção do conhecimento pelos alunos, compreendidos como sujeitos ativos no processo pedagógico, a proposta curricular foi organizada em quatro grandes áreas estruturadas a partir da centralidade do trabalho, objetivando estabelecer uma estreita relação com o real e, como decorrência, com as diferentes experiências de vida dos alunos. Assim, as áreas constituíram os elementos ordenadores das atividades pedagógicas e da organização dos materiais de apoio pedagógico aos alunos e professores, norteando os processos formativos.

Cada uma das áreas pretendeu contemplar objetivos específicos:

a) Comunicação, Cultura \& Sociedade "teve como objetivo estratégico possibilitar a apropriação do conceito de Sujeito nas suas dimensões individual e coletiva, considerando sujeito como produtor de bens, de cultura e de conhecimento" (Barbara, Miyashiro \& Garcia, 2004, p. 58);

b) em Conhecimento \& Tecnologia foram privilegiadas as "relações entre os temas: trabalho e técnica, sociedade e tecnologia, saberes e ciência, cultura e tecnologia, objetivando promover a reflexão sobre as conseqüências desse processo na vida" (p. 84);

c) a área Sujeito, Natureza \& Desenvolvimento apresentou como objetivo geral "a discussão sobre as relações entre Trabalho, Cultura e Sociedade" (p. 105);

d) em Gestão, \& Alternativas de Trabalho e Renda, um dos "propósitos foi promover a reflexão sobre a distinção entre desenvolvimento social e crescimento econômico" (p. 140), propondo, também, "uma análise crítica das for- mas de empreendimentos solidários existentes, suas possibilidades e limites" (ibidem).

Tomando como referência as necessidades geradas pela nova estrutura curricular, desvinculada da tradicional organização dos conteúdos escolares, o Programa Integração trouxe a proposta da unidocência, a qual, também segundo seus formuladores, não desconsiderava as especificidades das diferentes áreas do conhecimento, nem tampouco desqualificava a formação original dos educadores - todos com formação em nível superior. Para o Programa, a unidocência deveria ser compreendida como "uma possibilidade de nos desafiarmos para uma prática pedagógica integral" (idem, p. 36), como expressão da combinação dos conhecimentos trazidos pelos educadores, a serem articulados com a concretude da vida societária, "pressupondo as trocas e construção coletiva de conhecimento durante todo o percurso formativo para apropriação da síntese dos conhecimentos historicamente acumulados e a reelaboração de novos conhecimentos" (idem, ibidem).

No caso específico do Integração do SINTTEL$\mathrm{RJ}$, ocorreram adaptações à proposta original, formuladas a partir das vivências dos educandos e educadores e, em particular, das dificuldades enfrentadas para realizar, na prática, a concepção originalmente apresentada pela Secretaria Nacional de Formação da CUT. Tais adaptações centraram-se nos seguintes pontos: a) a elaboração de material didático próprio, complementar ao fornecido pela CUT, embora seguindo a mesma linha; b) o reordenamento de conteúdos, buscando estabelecer uma relação entre as quatro grandes áreas originais e as tradicionais áreas de conhecimento: ciências humanas, ciências exatas e ciências da natureza; foram incluídos, assim, conteúdos referentes à filosofia, à química, à linguagem, bem como informática educativa e conteúdos específicos do ramo da Telemática; c) finalmente, a proposta da unidocência, alterada desde a constituição do corpo docente, que, ao contrário do originalmente proposto (três educadores por núcleo, preferencialmente de áreas distintas), foi inicialmente composto por onze educado- 
res de diferentes áreas de formação. ${ }^{14}$ Desse modo, embora o SINTTEL-RJ tenha mantido, basicamente, a estrutura curricular original, ocorreu uma apropriação diferenciada de algumas das diretrizes nacionais do Programa formuladas pela SNF, do que decorreram distanciamentos e divergências entre as instâncias sindicais.

Consideramos importante valer-nos das reflexões apresentadas na sistematização elaborada pela coordenação do Integração do SINTTEL-RJ, para compreender as dificuldades enfrentadas pela equipe:

Percebemos na prática o desafio e as dificuldades de fazer parte de um programa que exige uma atividade docente para a qual o trabalhador em educação não foi formado. Como dar conta da transdisciplinaridade? Como integrar os diferentes conhecimentos sem nunca ter experimentado isso? [...] A implementação da metodologia proposta instigava parte da equipe a desejar a ousadia, outra parte fincava posição em concepções e práticas já experimentadas e talvez mais "cômodas" e mais "seguras". Esse embate, nem sempre fraterno, nos levou a redimensionar a ação pedagógica com todos os seus limites e possibilidades.

(Barros, Aguiar \& Rodrigues, 2003, p. 42)

Segundo entrevistas realizadas com seis professores que atuaram no SINTTEL-RJ, o planejamento original partiu, em certa medida, de uma visão idealizada tanto dos alunos quanto dos professores. Assim, era suposto que os alunos que procurariam o curso seriam trabalhadores vinculados aos diferentes ramos produtivos e ligados aos sindicatos, fatores que concorreriam para um razoável patamar comum, tanto no domínio mínimo de conhecimentos necessários aos campos profissionais quanto nas identidades políticas com relação ao ideário da CUT, o que, como já destacamos, não se verificou.

${ }^{14}$ Quatro professores de ciências sociais e humanas, um da área de códigos e linguagens, três de ciências da natureza e matemática, e três profissionais de telecomunicações.
Do mesmo modo, esperava-se dos professores que se apresentaram para atuar no Programa uma identidade político-ideológica que, o mais das vezes, não possuíam. Tais fatores não constituíram impedimento para realização da proposta, sobretudo pelo processo de formação continuada proposto pela CUT e implementado pelo SINTTEL-RJ, mas exigiram um diálogo efetivo com a realidade e com as condições objetivas de trabalho, e o enfrentamento de embates de diferentes ordens: entre os coordenadores, a equipe pedagógica e professores; com a coordenação nacional; e com alguns alunos que afirmavam não ter procurado o curso para "discutir política".

Por outro lado, dos oito professores que responderam o questionário aplicado pela equipe de pesquisa, sete demonstraram que, apesar das dificuldades enfrentadas, a proposta pedagógica se apresentou estimulante e foi, genericamente, acolhida de modo bastante positivo. No mesmo questionário, cinco professores declaram que uma grande dificuldade enfrentada por eles para a realização da proposta decorria da própria formação e das práticas vivenciadas nas escolas tradicionais.

Considerando-se a complexidade da proposta teórico-metodológica, bem como a expectativa de posicionamento político dos docentes, podemos afirmar que, no que tange especificamente à formação dos professores, verificou-se que, pelo menos para o conjunto de docentes que atuaram no SINTTEL-RJ, essa formação não foi considerada suficiente. No questionário mencionado, quatro professores declaram ser necessário maior tempo dedicado à formação, dado o caráter inovador da proposta. Nas entrevistas realizadas, também a questão do tempo foi apontada como um problema a ser enfrentado, muitas vezes sem êxito. A formação inicial restringiu-se a três dias de trabalho em São Paulo, complementada com reuniões conduzidas pela equipe pedagógica do Sindicato no Rio de Janeiro, e por outros encontros promovidos pela CUT, dos quais a maior parte dos professores não pôde participar em decorrência de outros compromissos de trabalho. Os professores incorporados posteriormente, em substituição aos que se afastaram, 
contaram apenas com a formação continuada, ao longo do processo.

Entretanto, o material produzido pela SNF para a formação dos professores - Cadernos de orientação metodológica e Coletâneas de textos-subsídios para o educador - foi por eles considerado bastante rico, oferecendo aportes teóricos necessários para uma atuação mais afinada com os objetivos do Programa (e da CUT) e propiciando possibilidades de reflexão sobre numerosas questões de caráter socioeconômico. O decorrer do curso, entretanto, demandou um tipo de envolvimento que, associado às outras atividades profissionais dos professores, não permitiu o necessário aprofundamento dos estudos. Recai-se, nesse caso, na situação que caracteriza, no mais das vezes, o trabalho docente: falta de condições de trabalho compatíveis com as expectativas e demandas das propostas pedagógicas. De todo modo, é importante frisar que a participação ativa na experiência inovadora do Programa Integração constituiu, em si, um permanente e fecundo processo de formação, que propiciou aos professores significativo avanço em relação à formação anterior. Uma das professoras de linguagem, findo o processo, afirmou sentir-se "mais preparada e confiante para lidar com novas experiências"; e que a experiência permitiu-lhe superar tanto o "medo de ousar como educadora", quanto "muitos conceitos e verdades absolutas de [sua] profissão".

Uma das principais dificuldades apontadas pelos professores referiu-se à questão da unidocência. Consideraram que, embora anunciada e defendida pela SNF como o coroamento de uma longa reflexão sobre a prática docente, o conteúdo da proposta não estava suficientemente claro, mesmo para a CUT. Consideraram-na rica e desafiadora, tendo, efetivamente, mobilizado os professores, mas sua formulação carecia, ainda, de aprofundamento teórico, como também de melhores processos de partilha de seus fundamentos com todo o conjunto da equipe executora.

Diante das questões suscitadas acerca da unidocência, bem como das soluções alternativas que a equipe do Rio de Janeiro buscou encontrar, consideramos que a proposta apresentada pela SNF é uma questão a ser ainda efetivamente enfrentada, de modo a serem compreendidos plenamente seus pressupostos e sua real viabilidade. Para tanto, faz-se necessário tomar como princípio que a educação dos trabalhadores não pode abrigar simplificações ou aligeiramentos. Devese, também, aprofundar, por exemplo, os estudos acerca dos conceitos de disciplinaridade e de transdisciplinaridade, sem o que o reordenamento das tarefas pedagógicas, carente de sustentação teórica, perde as potencialidades de criação e autonomia. Consideramos que o domínio das questões inerentes à transdisciplinaridade é que poderá propiciar a avaliação plena da proposta da unidocência, uma vez que, ao pretender uma abordagem pedagógica que representasse uma ruptura com os padrões escolares, o Programa Integração não considerou suficientemente o fato de que a abordagem transdisciplinar não nega a disciplinaridade, mas, ao contrário, parte dela para formular novas análises e sínteses.

Ademais, as especificidades das áreas de conhecimento não podem ser ignoradas, sob pena de que a perspectiva de superação da estrutura disciplinar transforme-se, mesmo que de forma involuntária, em uma proposta de atuação docente ancorada na idéia de polivalência, da qual irá decorrer uma ação educativa de caráter superficial. Acreditamos que, para se concretizar de forma plena a proposta aqui analisada, faz-se necessário compreender que a ruptura da lógica disciplinar se dá a partir da abordagem dos diferentes conhecimentos como partes integrantes e integradas de um todo que se expressa na própria vida societária, a qual, para ser apreendida em sua complexidade, exige a construção coletiva do conhecimento a partir das diferentes e específicas contribuições de cada um.

Tal perspectiva poderia dar origem a um processo de prática coletiva da docência, em certa medida anunciada pelo SINTTEL-RJ ao propor aulas em parceria, nas quais professores, articulando seus conhecimentos de referência, abordavam uma temática comum. No caso analisado, as maiores dificuldades para a ruptura com os limites da formação original foram verificadas pelos professores da área de ciências exa- 
tas, conforme explicitado nas entrevistas e questionários. Chama a atenção, também, o fato de que 22 alunos (dos 113 que responderam o questionário referido), ao serem indagados sobre aspectos negativos do curso ou o que consideravam necessário mudar no mesmo, mencionaram a necessidade de mais aulas na área das ciências exatas, com ênfase destacada na matemática. Entretanto, os próprios professores dessa área consideram que o caminho apontado pelo Integração pode ser explorado, com resultados positivos, a partir de um suporte teórico-metodológico mais consistente, que consideram ser necessário ainda construir.

Podemos considerar pertinente o que afirma a SNF:

O estudo da Matemática, no seu viés tradicional, já se mostrou ineficiente e impróprio na medida em que se restringe aos limites da repetição, levando a um aprendizado mecânico. Os educandos, assim como os educadores, trazem repertórios da linguagem matemática, mais ou menos sistematizados, que em diversas situações são utilizados para a solução de problemas do cotidiano. (CUT, 2001, p. 47)

Do apreendido a partir das declarações de educadores e educandos do Programa Integração realizado pelo SINTTEL-RJ, destaca-se o fato de que há um desafio a ser enfrentado e que se coloca, potencialmente, para todos, como uma possibilidade de "superar as barreiras do pensamento tradicional, que prevalece na educação, e promover mudanças", conforme afirmou, em resposta ao questionário, um professor de física, membro da equipe do SINTTEL-RJ. Na mesma direção se destaca o depoimento de outro professor, vinculado à formação profissional em Telemática, que afirmou ter aprendido, ao longo do processo formativo vivenciado no Integração, "que o planejamento articulado das diversas disciplinas é possível" e que pôde desvencilhar-se, em sua prática docente, de "alguns paradigmas que carregava devido à formação tecnológica". A positividade da proposta é também destacada por uma professora que valorizou muito a "oportunidade de tratar a matemática de uma maneira mais significativa, dirigida para a realidade e as necessidades dos educandos".

Um ponto que não pode deixar de ser destacado refere-se à avaliação dos alunos do Programa Integração - Ramo Telemática do Rio de Janeiro, feita pelos professores. Consideram eles que, comparativamente aos de outros cursos, em particular das redes públicas, os alunos do Programa destacaram-se de forma significativa no que concerne à construção de autonomia intelectual, ao amadurecimento afetivo e cognitivo e à postura ao mesmo tempo crítica e curiosa frente ao conhecimento. Outro ponto ressaltado, não só pelos professores do núcleo do SINTTELRJ, mas por todos os participantes do Seminário de Avaliação, ocorrido em dezembro de 2002, diz respeito à alteração qualitativa verificada na autonomia no âmbito da linguagem escrita e oral, que chegou a ser considerada, unanimemente, "fantástica".

Do mesmo modo, os alunos entrevistados declararam que a participação no Programa Integração foi decisiva para o desenvolvimento de nova postura frente às suas possibilidades de aprendizagem e ao conhecimento. Tomando a escola já conhecida como parâmetro de qualidade e estabelecendo comparações entre o vivenciado no Integração e as experiências anteriores, houve unanimidade quanto ao fato de que o curso, entre outras coisas, despertou-lhes o interesse e o desejo de prosseguir nos estudos, propiciando o resgate da autoconfiança, bem como a construção do sentimento de cidadania.

Consideramos que as alterações efetivamente verificadas ${ }^{15}$ nos planos cognitivo e afetivo, com base na experiência vivenciada pelos educandos e também pelos educadores no Programa Integração, decorreram, sobretudo, dos princípios norteadores da proposta

${ }^{15}$ Esta afirmação está fundamentada na análise das seguintes fontes: entrevistas concedidas pelos professores; questionários respondidos pelos alunos; entrevistas realizadas com 11 alunos e 237 Livros da vida, instrumento elaborado pelo SINTTELRJ para sistematização das experiências, auto-avaliação e avaliação do Programa pelos alunos. 
pedagógica. Entre eles, destacamos quatro aspectos. $\mathrm{O}$ primeiro refere-se à valorização dos conhecimentos acumulados pelos educandos ao longo de seus percursos formativos e tomados como ponto de partida do trabalho pedagógico. O segundo ponto a ser ressaltado consiste na compreensão de que as especificidades e diversidades dos educandos (faixa etária, escolaridade anterior, gênero, raça, etnia) não constituem entraves à vivência educativa, sendo, ao contrário, potenciadoras de trocas solidárias e do entendimento das diferenças como expressões da riqueza cultural que caracteriza a classe trabalhadora. Em terceiro lugar, a ênfase na construção coletiva e participativa do conhecimento, em oposição à lógica individualista e competitiva que marca, hoje, as práticas sociais, inclusive as de caráter escolar. Finalmente, a importante compreensão de que os jovens e adultos trabalhadores que buscam complementar sua escolaridade básica são capazes, desde que vivenciando experiências pedagógicas adequadas, de compreender textos produzidos por qualquer autor, do mesmo modo que podem, eles mesmos, exercer a condição de autoria. Essa perspectiva possibilitou tanto o contato dos alunos com autores como Antonio Candido, Émile Zola, Florestan Fernandes, Juan Bordenave e Wolfgang Haug, entre outros, quanto a incorporação de textos produzidos pelos educandos no conjunto de fichas geradoras de debate que subsidiou o trabalho em cada uma das quatro áreas a partir das quais se estruturou o currículo.

\section{Considerações acerca da educação profissional}

Segundo a Secretaria Nacional de Formação da CUT, a educação profissional não deve ser compreendida "como o domínio de uma ou mais técnicas, que têm como objetivo apenas satisfazer interesses práticos imediatos, mas como aumento da satisfação das múltiplas necessidades do ser humano e compreensão de que a informação em si não se configura em conhecimento" (CUT, 2001, p. 38). Conforme esta perspectiva, a organização curricular do Programa Integração pretendeu contemplar as questões relati- vas à educação profissional a partir da centralidade do trabalho, como já exposto, focalizando o tema nas quatro áreas em que foi organizado.

Não podemos ignorar o fato de que, uma vez inscrito na tarefa de elevar a escolaridade básica dos trabalhadores, o Integração, coerente com a visão de educação formalmente defendida pela CUT, não poderia deixar de tentar contemplar todas as dimensões da formação humana, deixando de priorizar, assim, as imposições do mercado. Nesse sentido, a proposta, em certa medida, subverteu a lógica do PLANFOR, uma vez que, segundo seus documentos, a CUT não visou oferecer formações focalizadas, de modo estrito, em demandas de caráter imediato e muitas vezes desprovidas de qualquer conteúdo efetivamente comprometido com a qualificação para o exercício profissional, características predominantes nos muitos cursos oferecidos por diferentes entidades com recursos do FAT.

Em contrapartida, tanto os dirigentes da CUT quanto os formuladores e executores do Programa não desconheciam o fato de que a proposta não possuía, em si, nem a perspectiva de gerar empregos, nem de possibilitar aos educandos o ingresso no mercado de trabalho, nos diferentes ramos. Daí, certamente, adveio a ênfase na área Gestão \& Alternativas de Trabalho e Renda, que, simultaneamente, oferecia ao Programa um desenho compatível com as exigências do MTE e atendia, supostamente, às necessidades dos alunos de proverem, por meio de diferentes atividades, sua subsistência.

No que diz respeito à formação profissional, a CUT considera que deve estar incorporada ao que denomina educação integral, que se amplia para

\footnotetext{
[...] incluir a elevação de escolaridade, a educação para o exercício da cidadania, a totalidade das dimensões que constituem a vida do trabalhador (econômica, social, cultural, política, subjetiva) e a proposta de lutar por políticas de emprego e por um modelo de desenvolvimento baseado na economia solidária e sustentável. (CUT, 2003, p. 140)
}

Além disso, a CUT também enfatiza, no mesmo documento, que a formação profissional, enquanto 
"elemento de acesso ao mercado de trabalho formal e como potenciador e promotor do trabalho e renda coletivos e autogestionários, é um instrumento fundamental para um trabalho decente e um desenvolvimento sustentável e solidário com qualidade de vida" (idem, p. 41).

Consideramos que, na realidade, a CUT, ao assumir o papel de executora de uma política pública marcada pela lógica que subtrai aos trabalhadores os direitos sociais conquistados, e mesmo o direito ao trabalho alienado, como é próprio do modo de produção capitalista, move-se num árduo terreno de incertezas que marca, inevitavelmente, suas propostas e ações. É nesse quadro que se localiza o Programa Integração e, nele, os objetivos específicos da educação profissional que se propõe oferecer aos trabalhadores.

Especificamente no caso do Programa Integração do SINTTEL-RJ, que ofereceu aos alunos a proposta de realização de um curso de elevação de escolaridade com qualificação básica em Telemática, verificou-se a tentativa de propiciar qualificação mínima em atividades referentes ao ramo produtivo, inclusive com a incorporação de professores da área, como já assinalado.

A Coordenação do Programa, no SINTTEL-RJ, reconhece, por um lado, que a formação profissional foi efetivamente prejudicada pela falta de recursos materiais; mas, por outro, considera que, no curso, não seria possível avançar mais, devido ao pouco tempo disponível. Essa constatação evidencia que, no caso da formação profissional, o SINTTEL-RJ não pode propiciar aos jovens e adultos trabalhadores, mesmo com as restrições inerentes ao tipo de curso oferecido, uma base de conhecimentos compatível com os avanços tecnológicos do ramo produtivo em que se inscreve e para o qual apresenta propostas de alto nível científico-tecnológico. Segundo uma das coordenadoras pedagógicas do Programa:

O que queremos [no SINTTEL-RJ] é que nossos cursos se apresentem de tal forma ao trabalhador que, ao seu final, ele possa ter apreendido como trabalhar com cada uma das técnicas/tecnologias das mais diversas funções dos cur- sos oferecidos, mas também compreenda como essa função veio se transformando ao longo do tempo e por que razões; além de conhecer um pouco mais da história do próprio setor de Telecomunicações. (Rodrigues, 1999, p. 23)

No documento de sistematização elaborado pela Coordenação, Construindo caminhos na educação do trabalhador: a experiência do Integração-RJ (Barros, Aguiar \& Rodrigues, 2003), a mesma questão é mencionada. Inicialmente, convergindo com visão anunciada pela CUT, é afirmado que a formação profissional foi tratada como uma das dimensões da educação integral e que, nesse sentido, "podemos dizer que avançamos, enfrentando, inclusive, uma leitura inicial, por parte dos alunos, que vislumbrava a qualificação profissional como uma solução individual para o emprego" (idem, p. 42).

As autoras, entretanto, não deixam de se referir aos problemas vivenciados, desde a existência de um único laboratório de informática para atender a mais de 200 alunos, o que dificultou a execução dos trabalhos, até as dúvidas que permaneceram quanto ao tratamento dado à questão. Refletindo sobre a formação profissional, destacam ser necessário, em outras experiências, "reconhecê-la com algumas especificidades que demandam dedicação, pesquisa e tempo diferenciados, que devem ser considerados numa concepção de educação que se pretenda integral" (idem, p. 38).

Podemos, assim, depreender que um dos objetivos anunciados pela coordenadora pedagógica, a partir do qual o SINTTEL-RJ, no conjunto de suas ações, pretendia que o trabalhador pudesse aprender como trabalhar com cada uma das técnicas/tecnologias, não pôde ser alcançado nesse caso. Na realidade, por um conjunto de limites, o Programa Integração - Ramo Telemática-RJ não qualificou, efetivamente, os alunos para a atuação profissional coadunada com as transformações tecnológicas do campo das telecomunicações e fartamente apontadas nos documentos elaborados pelas entidades sindicais.

Embora nas respostas de $86 \%$ dos questionários aplicados, bem como nas entrevistas realizadas, os alunos tenham avaliado de forma extremamente po- 
sitiva o curso como um todo, houve unanimidade quanto ao fato de registrarem como problema a pouca ênfase na formação profissional. Destaca-se, assim, que embora os educandos tenham compreendido, com base nas reflexões suscitadas ao longo do curso, que a formação profissional não se apresenta como solução individual para o desemprego, também não deixam de demandar um conjunto de conhecimentos específicos que lhes possibilite buscar alguma forma de inserção no mercado, mesmo dominando as condições cognitivas e afetivas básicas para criticá-lo e identificar os inúmeros limites que lhes são inerentes.

\section{Conclusão}

Abordamos, neste trabalho, aspectos relevantes do Programa Integração, por considerá-lo uma contribuição bastante significativa para a reflexão sobre a educação dos jovens e adultos trabalhadores. Não se trata de indicar elementos de caráter teórico ou procedimentos didáticos que possam ser apropriados de forma isolada ou acrítica, mas de ressaltar a importância e a necessidade de que sejam aprofundados estudos sobre uma proposta que, se por um lado apresenta limites a serem superados, por outro abriga múltiplas possibilidades de avanço para a educação comprometida, de modo efetivo, com as necessidades dos trabalhadores.

O Programa Integração, independentemente das dificuldades encontradas para sua implementação, da fragilidade de algumas formulações, e também do fato de decorrer de uma iniciativa do movimento sindical por muitos considerada imprópria, constituiu, sem dúvida, um trabalho que não pode ser ignorado. Podemos assim afirmar que, no rico espaço das contradições inerentes aos fatos sociais, o movimento sindical e a CUT em particular, a partir de uma questionável política de formação profissional implementada pelo Estado, propôs e concretizou um conjunto de ações educativas - especificamente as voltadas para a elevação da escolaridade básica - a partir do qual se qualificou com um aprofundamento teórico e com uma ampliação de interlocutores não verificados, até então, no âmbito do novo sindicalismo.

Podemos considerar que as ações das entidades sindicais aqui abordadas representam uma resposta possível às necessidades postas pela atual crise vivida no mundo do trabalho, a qual exige novos caminhos de vinculação entre o movimento sindical e suas bases, num quadro crescente de desemprego e de precarização das condições de trabalho. Nesse processo coloca-se em discussão os efetivos compromissos do movimento sindical combativo - em particular da corrente hoje hegemônica em seu campo - com os princípios que foram anunciados e assumidos formalmente no advento do novo sindicalismo. Questões de tal ordem, entretanto, não desqualificam as contribuições que as entidades representativas dos trabalhadores nos oferecem acerca de sua própria educação.

Assim, podemos concluir valendo-nos das palavras de uma professora que fez parte da equipe do SINTTEL-RJ. Ao lhe perguntamos sobre o que sugeria para o Programa Integração, declarou: "Eu sugiro que essa experiência seja divulgada, rediscutida e aprimorada, para que um dia se torne uma referência de reflexão nas novas políticas educacionais".

SONIA MARIA RUMMERT, doutora em ciências humanas - educação pela PUC-Rio, é professora da Faculdade de Educação e do Programa de Pós-Graduação em Educação da Universidade Federal Fluminense. Coordena atualmente o Núcleo de Estudos, Documentação e Dados sobre Trabalho e Educação (NEDDATE) e o Curso de Especialização em Formação do Educador de Jovens e Adultos Trabalhadores. Publicações mais recentes: Educação e identidade dos trabalhadores: as concepções do capital e do trabalho (São Paulo: Xamã; Niterói: Intertexto, 2000); A hegemonia capitalista e a comunicação de massa (Movimento, Revista da Faculdade de Educação da UFF, n ${ }^{\circ}$ 5, maio de 2002, p. 63-94); Jovens e adultos trabalhadores e a escola, a riqueza de uma relação a construir. In: FRIGOTTO, Gaudêncio, CIAVATTA, Maria (orgs.). A experiência do trabalho e a educação básica (Rio de Janeiro: DP\&A, 2002, p. 117-130); Aspirações, interesses e identidade dos trabalhadores: elementos essenciais à construção da hegemonia (2004, disponível em: <www.uff. br/trabalhonecessario>). Organizadora da Coleção Educação de 
Jovens e Adultos Trabalhadores, lançada em abril de 2004 pela DP\&A. Com apoio do CNPq, desenvolve o projeto de pesquisa Educação básica e profissional de trabalhadores. Políticas públicas e ações do estado, do trabalho e do capital.E-mail: rummert@ alternex.com.br

\section{Referências bibliográficas}

AFFONSO, Cláudia, (2001). A CUT conselheira: tripartismo e formação profissional. Concepções e práticas sindicais nos anos 90. Dissertação de mestrado. Faculdade de Educação da Universidade Federal Fluminense.

ALMEIDA, Márcio Wholers, (1994). Reestruturação, internacionalização e mudanças institucionais das telecomunicações: lições das experiências internacionais para o caso brasileiro. Tese de doutorado. Instituto de Economia da Universidade Estadual de Campinas.

BARBARA, M., MIYASHIRO, R., GARCIA, S., (2004). Experiência de educação integral da CUT. Práticas em construção. Rio de Janeiro: DP\&A.

BARROS, Ruth Nazaré, AGUIAR, Lucília, RODRIGUES, Maria Cristina, (2003). Construindo caminhos na educação do trabalhador: a experiência do Integração/RJ. Rio de Janeiro: SINTTEL-RJ.

CUT - Central Única dos Trabalhadores, (2001). Bases do projeto político pedagógico do programa de educação profissional. São Paulo: CUT, Secretaria Nacional de Formação - SNF. , (2003). A intervenção da CUT nas políticas públicas de geração de trabalho, emprego, renda e educação dos trabalhadores: avaliação, resultados e ampliação de perspectivas. São Paulo: CUT/UNITRABALHO.

CUT/FINEP, (2000). Reestruturação produtiva, política industrial e contratação coletiva nos anos 90. As propostas dos trabalhadores. Caderno Síntese $1^{a}$ fase: Telecomunicações, 1999; Caderno Síntese $2^{\mathrm{a}}$ fase: Telecomunicações.

CUT/Integração, (2000). E agora José? Entenda o problema do desemprego no Brasil e as soluções para resolvê-lo. São Paulo: CUT.
DANTAS, Marcos, (1996). A lógica do capital da informação. Rio de Janeiro: Contraponto.

FITTEL - Federação Interestadual dos Trabalhadores em Telecomunicações, (1996). Caderno de Resoluções do VI CONTEL. Rio de Janeiro: FITTEL.

FRIGOTTO, Gaudêncio, (1999). Crise do trabalho, formação profissional e reforma do ensino. Em busca da EPSJV pública e estratégica. Caderno de Debates, Seminário de 13 a 15 de dezembro de 1999, Rio de Janeiro: FIOCRUZ/EPSJV, p. 45-60, dez.

INTEL - Instituto de Telecomunicações/SINTTEL-RJ - Sindicato dos Trabalhadores em Telecomunicações do Rio de Janeiro, (1999). Proposta de qualificação profissional na área de telecomunicações. Rio de Janeiro: INTEL.

JAMESON, Fredric, (1999). Cinco teses sobre o marxismo atualmente existente. In: WOOD, Ellen, FOSTER, John (orgs.). Em defesa da história: marxismo e pós-modernismo. Rio de Janeiro: Jorge Zahar Editor, p. 187-195.

, (1994). Espaço e imagem. Teorias do pós-modernismo e outros ensaios. Rio de Janeiro: Editora da UFRJ.

MANFREDI, Silvia, (2002). Educação profissional no Brasil. São Paulo: Cortez.

RODRIGUES, Maria Cristina de Paulo, (1999). Os sindicatos e a educação dos trabalhadores. Tecnologia Educacional, Rio de Janeiro, p. 22-25, out.-nov.-dez.

, (2002). Política nacional de telecomunicações nos anos 1980-90: é possível nadar contra a corrente? Dissertação de mestrado. Faculdade de Educação da Universidade Federal Fluminense.

SILVA, Cecília Maria da, (2004). Educação de jovens e adultos trabalhadores: a experiência do Programa Integração. Dissertação de mestrado. Faculdade de Educação da Universidade Federal Fluminense.

TUMOLO, Paulo Sergio, (2002). Da contestação à conformação. A formação sindical da CUT e a reestruturação capitalista. Campinas: Ed. da UNICAMP.

Recebido em abril de 2004 Aprovado em junho de 2004 
the adults of our study, school world and daily life world were represented as separated, as well as the mathematical knowledge generated in each of these contexts.

Key-words: ethnomathematics; adult basic education; quantitative and spatial representations

Maria Isabel Brandão de Souza Mendes e Terezinha Petrucia da Nóbrega

\section{Corpo, natureza e cultura:} contribuições para a educação Ao se discutir a construção teórica da relação entre os conceitos de estes conceitos, busca-se apontar possíveis contribuições para a educação. Ao conceber que estes conceitos se interpenetram através de uma lógica recursiva, que o corpo é uma construção biocultural, um corpo vivo, e ao compreender que os opostos, em vez de se isolarem, se complementam, se poderá reconhecer tanto a autonomia do corpo quanto a sua dependência com o meio, a cultura e a sociedade em que vive. Desse modo, a educação, ao perceber que não é possível ir em busca de um corpo isento de história, e ao reconhecer a responsabilidade que possui ao colaborar com a reescrita dessa história, tem o desafio de permitir desabrochar as subjetividades, abrindo espaços que possibilitem aflorar um ser que, ao modificar-se constantemente, provoca mudanças no ambiente, na sociedade, na cultura.

Palavras-chave: corpo; educação; epistemologia; natureza; cultura

\section{Body, nature and culture:} contributions for education In discussing the theoretical construction of the relation between the concepts of body, nature and culture, this article seeks to point to possible contributions for education. By conceiving that body, nature and culture are interwoven by a recursive logic, that the body is a biocultural construction, a living body, and by understanding that the opposites, instead of isolating themselves, complement each other, it should be possible to recognise both the autonomy of the body and its dependence on the environment, culture and the society in which it resides. In this way, by perceiving that it is not possible to look for a body exempt from history, and by recognising the responsibility which it has in collaborating with a rewriting of that history, education faces the challenge of permitting subjectivities to blossom, opening spaces which will allow a being to bloom who, by constant modification, provokes changes in the environment, society and culture.

Key-words: body; education, epistemology; nature; culture

Sonia Maria Rummert

Programa Integração: avanços e contradições de uma proposta de educação formulada pelos trabalhadores

Este artigo analisa o Programa Integração, desenvolvido pela Central Única dos Trabalhadores (CUT), no âmbito do Programa de Qualificação Profissional (PNQP). Aborda especificamente o caso do Programa Integração do Sindicato dos Trabalhadores em Telecomunicações do Rio de Janeiro, focalizando a problemática das telecomunicações no Brasil e suas repercussões junto aos trabalhadores e às suas entidades representativas. São também abordadas as contradições inerentes à opção da CUT pelo papel de executora de uma política de educação dos trabalhadores, materializada no Programa Nacional de Qualificação Profissional (PLANFOR), implementada pelo Estado, sob a hegemonia do ideário neoliberal. São analisados também os avanços e os limites das contribuições teórico-metodológicas do Programa Integração à educação de jovens e adultos trabalhadores, dando especial relevo às suas potencialidades.

Palavras-chave: educação básica e profissional de jovens e adultos trabalhadores; movimento sindical e educação; fundamentos teórico-metodológicos da educação de jovens e adultos trabalhadores.

Integration Programme: advances and contradictions in an educational proposal formulated by workers

The text analyses the Integration Programme, developed by the Workers Central Trade Union Organisation (CUT), within the context of the Programme of Professional Qualification (PNQR). It deals specifically with the way in which this programme was implemented by the Telecommunication Workers' Trade Union in Rio de Janeiro, focusing on the problem of telecommunications in Brazil and its repercussions on workers and on their representative entities. The contradictions inherent in CUT's option for the role of executor of a policy of workers' education, embodied in the National Programme of Professional Qualification (PLANFOR), implemented by the State under the hegemony of neoliberal inspiration are also discussed. The advances and limitations of the theoretical-methodological contributions of the Integration Programme to the education of adult and young workers are also dealt with, giving special emphasis to their potential.

Key-words: primary and professional education for young and adult workers; trade union movement and education; theoretical-methodological foundations of education for young and adult workers

Mauricio Rocha

Paradoxo da formação: servidão voluntária e liberação 